\title{
POCT-assisted Diagnosis for Acute Coronary Syndrome, Heart Failure and Venous Thromboembolism in Primary Care: A Longitudinal Analysis
}

Claudia Steiner ${ }^{1}$, Thomas D Szucs ${ }^{2}$, Markus Hug $^{3}$, Walter F Riesen ${ }^{4}$ and Yuki Tomonaga ${ }^{5}$

${ }^{1}$ Institute of Anaesthesiology and Intensive Care Medicine, Kantonsspital, 8501 Frauenfeld, Switzerland 2Institute of Pharmaceutical Medicine ECPM, University of Basel, 4057 Basel, Switzerland

${ }^{3}$ FMH Foederatio Medicorum Helveticorum (Swiss Medical Association), 2800 Delémont, Switzerland

${ }^{4}$ Institute of Clinical Chemistry and Haematology, Kantonsspital, 9007 St. Gallen, Switzerland

${ }^{5}$ Institute of Social and Preventive Medicine, University of Zurich, 8001 Zürich, Switzerland

\begin{abstract}
Objective: Evaluating symptoms indicating acute Coronary Syndrome (ACS), Heart Failure (HF) or Venous Thromboembolism (VTE) poses a particular challenge at primary care level. Cardiac troponin T (cTnT), N-terminal pro-brain natriuretic peptide (NT-proBNP) and D-dimer serve as crucial diagnostic tools in such assessments. Evidence of the clinical benefit of 3-in-1 Point-of-Care Testing (POCT) for these biomarkers are very limited. The current study is to further investigate the benefit of POCT-assisted diagnosis for cardiovascular risk stratification in primary care.
\end{abstract}

Methods: In the first phase of a previously reported prospective multicentre controlled trial, primary care physicians were randomised to POCT assisted diagnosis or conventional diagnosis (controls). In the second phase, the controls received the POCT analyser and continued patient recruitment. The accuracy of the working diagnosis made during the baseline consultation of adults presenting with the respective symptoms was evaluated in a followup examination. The resulting accuracy was compared with the accuracy from the controls.

Results: Controls and POCT patients were similar in terms of baseline characteristics, symptoms and pre-existing diagnoses, but differed in working diagnosis frequencies. After the follow-up visit, except for the musculoskeletal problems, which were more prevalent in the controls, no statistically significant difference could be determined in regard to the confirmed diagnosis frequencies. In the POCT group, working diagnoses were more frequently correct $(79.2 \%$ vs. $59.6 \%, p<0.001)$ and diagnostic accuracy for ACS, HF, and VTE was higher $(58.3 \%$ vs. $45.2 \%, p<0.001)$.

Conclusion: The POCT device improved the diagnostic accuracy for patients with symptoms indicative of ACS, HF, or VTE.

Keywords: Point-of-care testing; Primary care; Cardiovascular biomarkers; Acute coronary syndrome; Heart failure; Venous thromboembolism; Sensitivity; Specificity

\section{Introduction}

The evaluation of patients with chest pain and/or dyspnoea is a routine part of primary care practice. These cardinal symptoms can be caused by the following diseases and disorders: stable angina pectoris, infections of the upper respiratory tract, myocardium or pericardium, pneumothorax, exacerbated COPD, gastrointestinal disease, musculoskeletal pain and panic disorder. The three most important differential diagnoses are Acute Coronary Syndrome (ACS), Heart Failure (HF) and Venous Thromboembolism (VTE) [1-4]. Establishing a reliable primary care diagnosis on the basis of clinical findings and the readily available diagnostic tools, such as ECG and X-ray, can be difficult. A number of useful cardiovascular biomarkers help facilitate the diagnosis and more are currently under development $[5,6]$. The most frequently employed biomarkers in this context are cardiac troponin $\mathrm{T}$ (cTnT), N-terminal pro-brain natriuretic peptide (NT-proBNP) and D-dimer [7-9]. New multifunctional devices are capable of measuring all three in a matter of minutes [10].

As a protein found only in the heart, $\mathrm{cTnT}$ is a highly specific and sensitive biomarker of myocardial damage and, if elevated, diagnoses myocardial infarction in the setting of myocardial ischemia (ST changes, chest pain) [11-14]. In addition, cTnT is recognised as an important prognostic marker in ACS [15-18].

NT-proBNP enables rapid differentiation between cardiac and non-cardiac causes of dyspnoea, as a value in the normal range can rule out HF with near certainty $[19,20]$. Moreover, NT-proBNP has a high prognostic value among patients with ACS. Elevated NT-proBNP at the point of initial presentation predicts an increased risk of mortality from myocardial infarction [21-24]. In combination with symptoms, clinical findings, ECG and troponin, it also aids in the risk stratification of patients with ACS and non ST-segment elevation myocardial infarction (NSTEMI) [25].

D-dimers are degradation by-products of fibrinolysis, which are typically elevated in patients with VTE (deep vein thrombosis (DVT) and Pulmonary Embolism (PE)). In ambulatory patients with a low pretest probability, a negative $\mathrm{D}$-dimer value can safely rule out DVT and PE [26]. As increased D-dimer levels are seen in many other non-thrombotic situations such as pregnancy, malignancies, sepsis, pneumonia, erysipelas and others, the specificity of the D-dimer test is low [27].

*Corresponding author: Thomas D Szucs, Department of Pharmaceutica Medicine, University of Basel, 4057 Basel, Switzerland, Tel: +41 6126576 50; Fax: +416126176 55; E-mail: thomas.szucs@unibas.ch

Received January 24, 2015; Accepted April 21, 2015; Published April 28, 2015

Citation: Steiner C, Szucs TD, Hug M, Riesen WF, Tomonaga Y (2015) PPOCTassisted Diagnosis for Acute Coronary Syndrome, Heart Failure and Venous Thromboembolism in Primary Care: A Longitudinal Analysis. J Gen Pract S1: 003. doi:10.4172/2329-9126.S10003

Copyright: (c) 2015 Steiner C, et al. This is an open-access article distributed under the terms of the Creative Commons Attribution License, which permits unrestricted use, distribution, and reproduction in any medium, provided the original author and source are credited. 
Citation: Steiner C, Szucs TD, Hug M, Riesen WF, Tomonaga Y (2015) PPOCT-assisted Diagnosis for Acute Coronary Syndrome, Heart Failure and Venous Thromboembolism in Primary Care: A Longitudinal Analysis. J Gen Pract S1: 003. doi:10.4172/2329-9126.S10003

Page 2 of 7

The aim of this second analysis based in part on the previous study by Tomonaga et al. [10], was to confirm the benefit of POCT-assisted diagnosis for cardiovascular risk stratification in primary care. We assumed that the 40 Swiss general practitioners originally randomised as conventional diagnosis controls would attain a more accurate diagnosis of ACS, HF and VTE with the aid of POCT for cTnT, NTproBNP, and D-dimer.

\section{Methods}

\section{Study design and patients}

In a previous prospective multicentre cluster-randomised trial, by Tomonaga et al. [10], conducted in the Canton of Zurich (Switzerland) from May 2006 to August 2007, 33 primary care practices (39 physicians) were assigned to diagnostic aid from a POCT analyser and 35 primary care practices ( 40 physicians) were assigned to conventional diagnosis employing best clinical practice (controls) [10]. In August 2007, the controls received the same diagnostic device and continued patient recruitment until August 2008. The present analysis thus represents a before-and-after comparison of the same 40 physicians.

All adult patients presenting in the randomised primary care practices between May 2006 and August 2008 with chest pain, tightness, shortness of breath and other symptoms indicating a potential cardiovascular event were encouraged to take part in the study. All individuals included in the study gave their prior written consent. In addition, the study received approval from the local medical ethics committee (Kantonale Ethikkommission Zürich), in accordance with the Declaration of Helsinki (1996) and Good Clinical Practice guidelines. Excluded from the study were patients with a presentation $>5$ days after symptom onset, severe renal insufficiency, recent anticoagulant treatment and/or ongoing cancer therapy. The cited exclusion criteria were chosen to minimise the distortion of results stemming from a positive or negative influence on the biomarkers due to secondary diagnoses or treatments [28-30]. During the initial consultation, the general practitioner established the patient's medical history, principal symptoms and a comprehensive clinical status. It was up to the treating physician to decide whether to order such additional tests as ECG, conventional X-ray and, in the second phase of the study, analysis of the three biomarkers (the physician had the possibility to choose if and which biomarker test was necessary). The results of the initial consultation formed the basis for a working diagnosis in the following five categories: ACS, HF, VTE, musculoskeletal or other problems. At least three weeks after the baseline consultation, the same physician re-evaluated his or her working diagnosis in a followup examination. Additionally taking into account the results of any hospitalisations and/or further examinations by specialists, the followup examination yielded the confirmed diagnosis.

\section{Technical information}

After completion of the first study phase, the physicians were provided with the bedside Cardiac Reader ${ }^{\circledR}$ (Roche Diagnostics, Switzerland), a 3-in-1 device that determines cTnT, NT-proBNP and D-dimer in heparinised venous blood within 8 to 12 minutes. The quantitative measurement of the parameters was carried out in the ranges from $0.05-2.00 \mathrm{ng} / \mathrm{ml}, 60-3000 \mathrm{pg} / \mathrm{ml}$ and $0.1-4.0 \mu \mathrm{g} / \mathrm{ml}$ with 0.1 $\mathrm{ng} / \mathrm{ml}, 125 \mathrm{pg} / \mathrm{ml}$ and $0.5 \mu \mathrm{g} / \mathrm{ml}$ as the positive/negative cut-offs. The instruction of the general practitioners regarding operation of the POCT device and interpretation of the test results was always conducted by the same specialist from Roche Diagnostics to ensure consistency [10]. The quality of the tests was monitored in accordance with the internal and external quality controls mandated by Swiss federal law and the Swiss Commission for Quality Assurance in Medical Laboratories (QUALAB) [31].

\section{Statistical analysis}

The data were analysed using IBM SPSS 19.0 (IBM Corporation, Somers, NY, USA) and Microsoft Office Excel 2007 (Microsoft Corporation, Redmond, WA, USA). Chi-square tests and t tests were used for categorical and continuous variables, respectively. A two-tailed $p$ value of $<0.05$ was considered statistically significant. To evaluate the quality and performance of the diagnostic test, we generated receiver operating characteristic (ROC) curves, which were defined as test sensitivity on the $\mathrm{Y}$-axis and 1-specificity on the $\mathrm{X}$-axis. The area under the ROC curve (AUC) combining sensitivity and specificity was used to assess the overall performance of the diagnostic tests. This area was interpreted as the average sensitivity value for all potential specificity values [10]

\section{Results}

\section{Study population and baseline characteristics}

Of the 302 patients included in the study from May 2006 to August 2008, 151 (50\%) were recruited as controls and diagnosed conventionally, whereas the remainder were assigned to the POCT group and received a diagnosis supported by the analysis of cTnT, NTproBNP and/or D-dimer. The relevant baseline characteristics of age, gender, body mass index, creatinine, glucose, triglycerides, HDL and LDL did not differ significantly between the two groups. The interval between symptom onset and baseline visit was longer in the POCT group because some patients presented over 5 days after symptom onset (non-inclusion criterion). We contacted the practices for specific explanations. In almost all cases the patients had visited the physician in the previous weeks/months ( $>>5$ days) with cardiovascular problems. Due to new or exacerbated symptoms (on setting in the previous 5 days) they revisited their physician who reported the date of their first or previous visit incorrectly. After patients with incorrect symptom onset were excluded, the average interval between symptom onset and baseline visit became similar in the two groups (Table 1).

\section{Presenting symptoms}

The majority of patients in both groups presented with the principle symptoms of ACS, namely acute chest pain, tightness, pressure or squeezing in the chest and/or dyspnoea. Other symptoms typical of manifest heart failure alongside dyspnoea, such as oedema, distended neck veins, nocturia and cyanosis, were rarely documented. The groups statistically differed in acute chest pain, tightness, pressure/squeezing in the chest, and neck vein congestion (Table 2).

\section{Medical history}

The most frequently recorded cardiovascular risk factors were arterial hypertension, diabetes mellitus and current smoking. Hypertension, heart failure and smoking seemed to be more prevalent in the POCT patients, whereas thrombosis/embolism and pathological ECG were more prevalent in the controls. However no statistically significant difference was found between the two groups (Table 3).

\section{Working and confirmed diagnoses}

The frequencies of the working diagnoses between the two groups were similar for $\operatorname{HF}(p=0.850)$, VTE $(p=0.219)$ and MS $(p=0.681)$ (Figure 1). In contrast, in the POCT group there were significantly 
Citation: Steiner C, Szucs TD, Hug M, Riesen WF, Tomonaga Y (2015) PPOCT-assisted Diagnosis for Acute Coronary Syndrome, Heart Failure and Venous Thromboembolism in Primary Care: A Longitudinal Analysis. J Gen Pract S1: 003. doi:10.4172/2329-9126.S10003

\begin{tabular}{|c|c|c|c|}
\hline \multirow{4}{*}{ Variable } & Controls & РОCT & \multirow{4}{*}{$P$ value } \\
\hline & $n=151$ & $n=151$ & \\
\hline & $n(\%)$ & $n(\%)$ & \\
\hline & or mean \pm SD & or mean \pm SD & \\
\hline Men & $83 / 143(58.0)$ & $83 / 148(56.1)$ & 0.735 \\
\hline Age (years) & $64 \pm 17$ & $61 \pm 16$ & 0.424 \\
\hline Body mass index $\left(\mathrm{kg} / \mathrm{m}^{2}\right)$ & $27 \pm 6$ & $27 \pm 5$ & 0.797 \\
\hline Glucose (mmol/l) & $6.3 \pm 2.1$ & $6.1 \pm 2.0$ & 0.403 \\
\hline Creatinine $(\mathrm{mmol} / \mathrm{l})$ & $84.4 \pm 22.4$ & $81.8 \pm+20.2$ & 0.285 \\
\hline $\begin{array}{l}\text { High-density lipoprotein } \\
(\mathrm{mmol} / \mathrm{l})\end{array}$ & $1.4 \pm 0.5$ & $1.3 \pm 0.5$ & 0.640 \\
\hline $\begin{array}{l}\text { Low-density lipoprotein } \\
\text { (mmol/l) }\end{array}$ & $3.3 \pm 1.0$ & $3.0 \pm 1.3$ & 0.247 \\
\hline Triglycerides (mmol/l) & $1.7 \pm 1.0$ & $1.9 \pm 0.9$ & 0.982 \\
\hline $\begin{array}{l}\text { Interval between symptom } \\
\text { onset and baseline visit (all } \\
\text { patients, days) }\end{array}$ & $1.7 \pm 1.7$ & $2.2 \pm 8.2$ & 0.194 \\
\hline $\begin{array}{l}\text { Interval between symptom } \\
\text { onset and baseline visit } \\
\text { (patients presenting }<5 \text { days } \\
\text { after symptom onset, days) }\end{array}$ & $1.5 \pm 1.4$ & $1.3 \pm 1.5$ & 0.228 \\
\hline Time period & $\begin{array}{l}\text { May 2006-August } \\
2007\end{array}$ & $\begin{array}{l}\text { August } \\
\text { 2007-August } 2008\end{array}$ & \\
\hline
\end{tabular}

Table 1: Baseline demographics, clinical chemistry and interval between symptom onset and baseline presentation.

\begin{tabular}{|c|c|c|c|}
\hline \multirow{3}{*}{ Symptome } & Controls & POCT & \multirow{3}{*}{$P$ value } \\
\hline & $n=151$ & $n=151$ & \\
\hline & $n(\%)$ & $\mathrm{n}(\%)$ & \\
\hline Acute chest pain & $96(64)$ & $75(50)$ & 0.015 \\
\hline $\begin{array}{l}\text { Tightness, pressure, or } \\
\text { squeezing in the chest }\end{array}$ & $92(61)$ & $64(42)$ & 0.001 \\
\hline Dyspnoea & $69(46)$ & $53(35.1)$ & 0.061 \\
\hline Heartburn-like sensation & $19(13)$ & $19(13)$ & 1.000 \\
\hline $\begin{array}{l}\text { Heaviness and tension } \\
\text { sensations in the leg }\end{array}$ & $5(3)$ & $6(4)$ & 0.759 \\
\hline Calf pain & $4(3)$ & $10(7)$ & 0.101 \\
\hline Neck vein congestion & $4(3)$ & $0(0)$ & 0.044 \\
\hline Oedema & $9(6)$ & $9(6)$ & 1.000 \\
\hline Nocturia & $4(3)$ & $1(1)$ & 0.176 \\
\hline Cyanosis & $3(2)$ & $1(1)$ & 0.317 \\
\hline
\end{tabular}

Table 2: Presenting symptoms.

fewer ACS diagnoses $(\mathrm{p}=0.006)$ and more other diagnoses (e.g. stable angina, pleuritis, pericarditis, viral infection, psychiatric problems; $\mathrm{p}=0.029)$ if compared to the controls.

In the confirmed diagnosis, the diagnoses of ACS, HF, VTE and other problems scarcely differed between the two groups $(p=0.845$, $\mathrm{p}=0.545, \mathrm{p}=0.296$ and $\mathrm{p}=0.251$ respectively) (Figure 2). Only MS problems showed a significant difference and were more prevalent in the controls ( $35.1 \%$ vs. $24.0 \%, p=0.035$ ). In both groups, the majority of the patients were diagnosed with either MS or other problems.

\section{Diagnostic Accuracy of the Working Diagnosis}

In the POCT group, 118/151 (79.2\%) working diagnoses were correct compared to $90 / 151(59.6 \%)$ in the control group $(\mathrm{p}<0.001)$. Considering the three most important differential diagnoses ACS, HF and VTE, $58.3 \%$ of the working diagnoses were correct in the POCT group and $45.2 \%$ in the control group ( $<<0.001)$, with 25 false positive diagnoses (41.7\%) in the POCT group and 40 false positive diagnoses $(54.8 \%)$ in the control group. For the remaining working diagnoses (MS or other problems), there were $83 / 89$ (93.3\%) correct diagnoses

in the POCT group and $57 / 78(73 \%)$ in the control group $(\mathrm{p}<0.001)$. The sensitivity was higher in the POCT group for all working diagnoses except ACS and VTE (Table 4). The specificity was similar for all working diagnoses in both groups, except for ACS, which exhibited much better specificity in the POCT group. The Negative Predictive Values (NPV) for ACS, HF and VTE were practically identical. Overall, the accuracy of the working diagnoses in the POCT group was somewhat better than in the control group. Compared to the aforementioned predecessor study by Tomonaga et al. [10], however, the results of this second before-andafter analysis were less pronounced.

\section{Biomarker Performance in the POCT group}

Considering the sensitivity, specificity and NPV of all cardiovascular biomarkers in the POCT group, it is clear that the sensitivity for the confirmed diagnoses was markedly higher than for the working diagnoses, especially for the ACS diagnoses. The NPV was only minimally higher and the specificity was nearly identical in both groups. In terms of individual biomarkers, the cTnT test exhibited a higher diagnostic power for the confirmed diagnoses than the working diagnoses: the sensitivity was $40 \%$ higher while the NPV was $10 \%$ higher (Table 5). One patient had a false-negative result and risked a wrong diagnosis. Despite the false-negative result, the patient was diagnosed correctly based on his medical history and symptoms.

Unlike the cTnT test, NT-proBNP results were nearly identical in the working diagnoses and the confirmed diagnoses with a sensitivity of $92-93 \%$, specificity of $65-68 \%$ and NPV of $93 \%$. Only one patient received a false negative test. It was an 88 -year-old female who had a history of angina pectoris and diabetes and polymedication (ACE inhibitors, beta-blockers, oral anti-diabetic medication). Again, despite the false-negative result, the patient was diagnosed correctly based on her medical history and symptoms. The sensitivity of the $\mathrm{D}$-dimer test was high. Only one patient had a false-negative test. He was a male, 65 years old, with a BMI of $38 \mathrm{~kg} / \mathrm{m}^{2}$ and a medical history of DVT. He was correctly diagnosed based on his history and symptoms. Sixteen of 49 individuals with positive $\mathrm{D}$-dimer were not found to have thrombosis, which is reflected in a specificity of $75 \%$.

The cTnT ROC curve based on the confirmed diagnoses exhibited an irregular shape as the physicians often simply recorded the result as

\begin{tabular}{|c|c|c|c|}
\hline & Controls & POCT & \multirow{2}{*}{ P value } \\
\cline { 2 - 3 } & $\mathbf{n = 1 5 1}$ & $\mathbf{n = 1 5 1}$ & \\
\cline { 2 - 3 } & $\mathbf{n}(\%)$ & $\mathbf{n}(\%)$ & \\
\hline Myocardial infarction & $11(7)$ & $13(9)$ & 0.670 \\
\hline Angina pectoris & $15(10)$ & $12(8)$ & 0.545 \\
\hline Peripheral arterial disease & $5(3)$ & $2(1)$ & 0.251 \\
\hline Aneurysm/dissection & $2(1)$ & $1(1)$ & 0.562 \\
\hline Hypertension & $23(15)$ & $34(23)$ & 0.106 \\
\hline Diabetes mellitus & $15(10)$ & $17(11)$ & 0.708 \\
\hline Smokers & $24(16)$ & $32(21)$ & 0.236 \\
\hline $\begin{array}{c}\text { Chronic obstructive } \\
\text { pulmonary disease }\end{array}$ & $5(3)$ & $1(1)$ & 0.099 \\
\hline $\begin{array}{c}\text { Pathological } \\
\text { electrocardiagram }\end{array}$ & $59(39)$ & $48(32)$ & 0.171 \\
\hline Heart failure & $5(3)$ & $13(9)$ & 0.052 \\
\hline Renal failure & $8(5)$ & $5(3)$ & 0.395 \\
\hline Thrombosis/embolisme & $13(9)$ & $6(4)$ & 0.097 \\
\hline Malignant tumor & $7(5)$ & $7(5)$ & 1.000 \\
\hline Hospitalisation in previous & $25(17)$ & $17(11)$ & 0.183 \\
\hline 12 month & & & \\
\hline
\end{tabular}

Table 3: Medical history. 
Citation: Steiner C, Szucs TD, Hug M, Riesen WF, Tomonaga Y (2015) PPOCT-assisted Diagnosis for Acute Coronary Syndrome, Heart Failure and Venous Thromboembolism in Primary Care: A Longitudinal Analysis. J Gen Pract S1: 003. doi:10.4172/2329-9126.S10003

Page 4 of 7

positive or negative $(<0.1 \mathrm{ng} / \mathrm{ml})$. In such cases positives and negatives values were arbitrarily entered as $0.1 \mathrm{ng} / \mathrm{ml}$ and $0.0 \mathrm{ng} / \mathrm{ml}$ respectively. The AUC of $89 \%$ demonstrated the high quality of the test (Figure 3). The ROC curves for NT-proBNP and D-dimer were more regular and showed AUCs of $86 \%$ and $91 \%$ respectively.

\section{Discussion}

The results of the current study emphasise the importance of POCT for cTnT, NT-proBNP and D-dimer in the evaluation of patients presenting in primary care practices with potential cardiovascular symptoms. Diagnoses were more accurate with the use of a POCT device. In particular, the POCT-assisted general practitioners were able to avoid numerous false positive working diagnoses of ACS, HF and

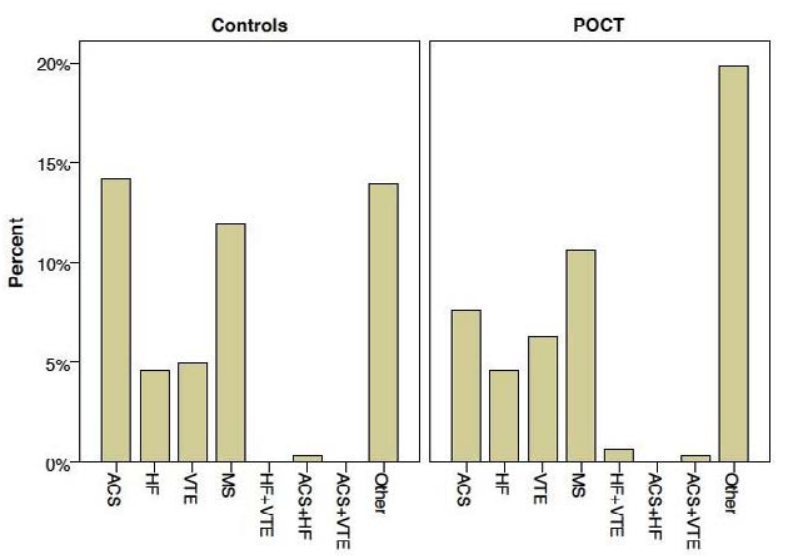

Figure 1: Working diagnoses at baseline. ACS diagnoses were more frequent and other diagnoses less frequent in the controls $(p=0.006$ and $p=0.029)$. HF, VTE and MS were similar in both groups $(p=0.850, p=219$ and $p=0.681$ respectively). One patient in the control group was diagnosed with both ACS and HF, one POCT patient with ACS and VTE and two patients in the POCT group with HF and VTE. (ACS, acute coronary syndrome; HF, heart failure; MS, musculoskeletal problems; VTE, venous thromboembolism).

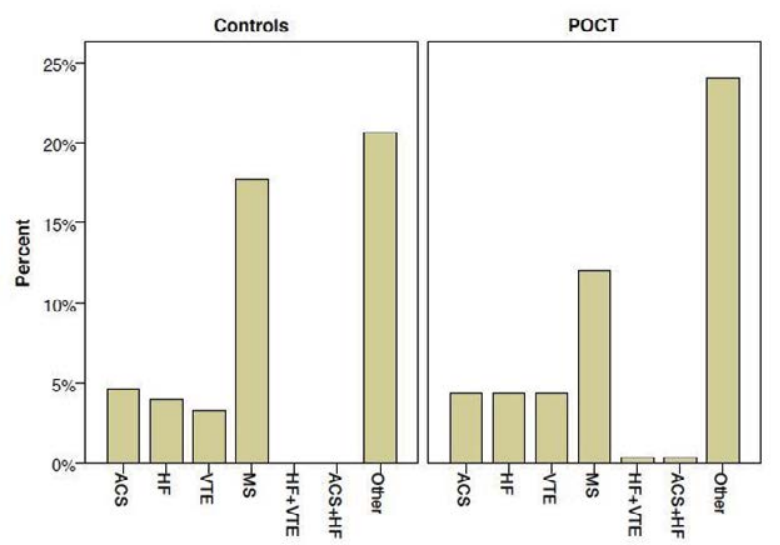

Figure 2: Confirmed diagnoses. The incidence of ACS, HF, VTE and other problems were similar in both groups $(p=0.845, p=0.545, p=0.296$ and $p=0.251$ respectively). Musculoskeletal and other problems were the predominant diagnoses in both groups. MS were significantly more frequent in the controls $(p=0.035)$. (ACS, acute coronary syndrome; HF, heart failure; MS, musculoskeletal problems; VTE, venous thromboembolism.

\begin{tabular}{|c|c|c|c|c|c|c|c|}
\hline & \multicolumn{2}{|c|}{ Sensitivity } & \multicolumn{2}{|c|}{ Specificity } & \multicolumn{2}{|c|}{ NPV } \\
\hline & & $\mathrm{n}$ & $\%$ & $n$ & $\%$ & $\mathrm{n}$ & $\%$ \\
\hline \multirow{2}{*}{ ACS } & POCT & $12 / 15$ & 80 & $124 / 136$ & 91 & $124 / 127$ & 98 \\
\hline & Controls & $14 / 14$ & 100 & $107 / 137$ & 78 & $107 / 107$ & 100 \\
\hline \multirow{2}{*}{$\mathrm{HF}$} & РOCT & $14 / 15$ & 93 & $134 / 136$ & 99 & $134 / 135$ & 99 \\
\hline & Controls & $10 / 12$ & 83 & $134 / 139$ & 96 & $134 / 136$ & 99 \\
\hline \multirow{2}{*}{ TE } & POCT & $11 / 15$ & 73 & $125 / 136$ & 92 & $125 / 129$ & 97 \\
\hline & Controls & $9 / 10$ & 90 & 135/141 & 96 & $135 / 136$ & 99 \\
\hline \multirow{2}{*}{ MS } & РОCT & $29 / 36$ & 81 & $111 / 114$ & 97 & $111 / 118$ & 94 \\
\hline & Controls & $34 / 53$ & 64 & $96 / 98$ & 98 & $96 / 115$ & 84 \\
\hline \multirow{2}{*}{ Other } & РОCT & $55 / 71$ & 77 & $75 / 78$ & 96 & $75 / 91$ & 82 \\
\hline & Controls & $37 / 62$ & 60 & $84 / 89$ & 94 & $84 / 109$ & 77 \\
\hline
\end{tabular}

Table 4: Diagnostic accuracy of the working diagnoses - sensitivity, specificity and NPV.

\begin{tabular}{|c|c|c|c|c|c|c|c|}
\hline \multirow{2}{*}{ Biomarker } & \multirow{2}{*}{$\begin{array}{c}\text { In relation } \\
\text { to }\end{array}$} & \multicolumn{2}{|c|}{ Sensitivity } & \multicolumn{2}{|c|}{ Specificity } & \multicolumn{2}{|c|}{ NPV } \\
\hline & & $\mathrm{N}$ & $\%$ & $\mathrm{~N}$ & $\%$ & $\mathrm{~N}$ & $\%$ \\
\hline \multirow{2}{*}{ CTnT } & $\begin{array}{l}\text { Working } \\
\text { ACS }\end{array}$ & $8 / 19$ & 42 & $83 / 89$ & 93 & $83 / 94$ & 88 \\
\hline & $\begin{array}{l}\text { Confirmed } \\
\text { ACS }\end{array}$ & 9/11 & 82 & $92 / 97$ & 95 & $92 / 94$ & 98 \\
\hline \multirow[b]{2}{*}{ NT-pro BNP } & Working HF & $13 / 14$ & 93 & $13 / 19$ & 68 & $13 / 14$ & 93 \\
\hline & $\begin{array}{c}\text { Confirmed } \\
\text { HF }\end{array}$ & $12 / 13$ & 92 & $13 / 20$ & 65 & $13 / 14$ & 93 \\
\hline \multirow{2}{*}{ D-dimer } & $\begin{array}{l}\text { Working } \\
\text { VTE }\end{array}$ & $17 / 19$ & 89 & $47 / 56$ & 84 & $47 / 49$ & 96 \\
\hline & $\begin{array}{l}\text { Confirmed } \\
\text { VTE }\end{array}$ & 10/11 & 91 & $48 / 64$ & 75 & $48 / 49$ & 98 \\
\hline
\end{tabular}

Table 5: Sensitivity, specificity and NPV of cTnT, NT-pro BNP and D-dimer in relation to the working and confirmed diagnoses of ACS, HF and VTE.
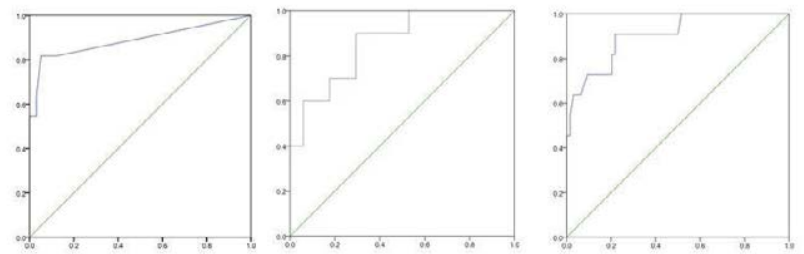

Figure 3: cTnT(left), NT-proBNP (center) and D-dimer (right) ROC curves. X-axis: 1-specificity; Y-axis: Sensitivity. Areas under the curv (AUC): $89 \%$ (95\% confidence interval [Cl]: $0.75-1.00), 86 \%(95 \% \mathrm{Cl}: 0.72-1.00)$ and 91\% (95\% Cl: 0.81-1.00)

VTE. This, in turn, meant that many additional diagnostic measures could be spared. Analysis of the three biomarkers cTnT, NT-pro BNP and $\mathrm{D}$-dimer in primary care settings offers a relevant diagnostic advantage by more reliably ruling ACS, HF and VTE in or out among a non-selected patient population. Overall, compared with the data stem from the study by Tomonaga et al. [10] the results of this second analysis where slightly less pronounced.

\section{Diagnoses of ACS}

Encompassing unstable angina pectoris, NSTEMI and ST-segment elevation myocardial infarction (STEMI), ACS is responsible for rising morbidity and mortality worldwide [32]. Coronary heart disease is the leading cause of death in western countries. In the United States, it was responsible for one in six deaths in 2007 [33]. A study conducted by Murray et al. [34] suggests that by the year 2020, it will become the main cause of death in developing countries as well. The rapid identification of patients with suspected ACS is critical for the 
Citation: Steiner C, Szucs TD, Hug M, Riesen WF, Tomonaga Y (2015) PPOCT-assisted Diagnosis for Acute Coronary Syndrome, Heart Failure and Venous Thromboembolism in Primary Care: A Longitudinal Analysis. J Gen Pract S1: 003. doi:10.4172/2329-9126.S10003

Page 5 of 7

initiation of evidence-based medical treatment, which has a major influence on clinical and economic outcomes [11,12,35]. Relying on symptoms to recognise acute myocardial infarction is often difficult, especially because a third of the patients present with other symptoms than chest pain [36]. In the current study, the number of ACS diagnoses was unexpectedly high among the working diagnoses, in particular in the control group. We surmised that the study topic may have sensitised physicians to typical and atypical chest pain as a potential cause of ACS, leading them to overestimate its incidence. In numerical terms, approximately two-thirds of the ACS working diagnoses in the control group were not confirmed in the follow-up examination. This was reflected in the high sensitivity and low specificity. In the POCT group, by contrast, fewer cases of ACS were suspected, which resulted in poorer sensitivity but a better specificity. In $90 \%$ of the POCT group and in $80 \%$ of the control group, ACS was correctly included or excluded. Overall, the data from this analysis based in part on the data of the previously reported trial by Tomonaga et al. [10] support the idea that measuring $\mathrm{cTnT}$ in combination with the clinical presentation, patient history and ECG enhances diagnostic accuracy, in line with the American College of Cardiology/American Heart Association guidelines on managing patients with unstable angina or NSTEMI and the European Society of Cardiology Guidelines for the diagnosis and treatment of non-ST-segment elevation ACS $[11,12]$. Except for the sensitivity results discussed above, our data reflect the $94 \%$ sensitivity and 97\% NPV of the cTnT test for ACS reported by Lüscher et al. [37] in 92 patients with chest pain, and the $100 \%$ sensitivity, $42 \%$ specificity and $100 \%$ NPV reported by Fehr et al. [38] in a cross-sectional study of asymptomatic haemodialysis patients. The high AUC value for the cTnT ROC curve was largely attributable to the high test specificity. To exclude ACS on the basis of a negative cTnT reading, at least 6 hours need to have elapsed following symptom onset (time to increase above the reference range). The maximum time limit up to which troponin can be used for diagnostic purposes is 5-7 days (time for biomarker level normalisation). Table 1 confirms that most patients fulfilled this time criterion.

\section{Diagnoses of HF}

$\mathrm{HF}$ is a growing health problem worldwide. According to the latest statistics, over 5.5 million Americans and approximately 15 million inhabitants in the 51 ESC member countries suffer from HF. The incidence of $\mathrm{HF}$ among those over 65 years of age is 10 per $1000[33,39]$. In addition, it is the most frequent cause of hospitalisation for people over 65 [33]. With effective treatments and lower mortality rates from hypertension and coronary heart disease, the two largest causes of HF, more people are surviving to experience HF in old age and hence the incidence and absolute numbers of patients with HF can be expected to rise significantly in coming decades [40]. The diagnosis of HF in a primary care context is difficult as symptoms and clinical examinations are often not sensitive enough to make a reliable diagnosis [41]. Furthermore, while echocardiography is the most frequently used and most dependable method of evaluating systolic and diastolic heart function $[39,42]$, the technique is relatively expensive and beyond the means of most general practitioners [42,43].

In our analysis, like the previous study by Tomonaga et al. [10], the diagnosis of HF in the POCT group exhibited high sensitivity, specificity and NPV. Specificity and NPV were also high in the control group. However, sensitivity was lower, suggesting that HF was better identified in the POCT group, presumably due to the NT-proBNP. The high AUC of the NT-proBNP ROC curve (Figure 3) reflected the high diagnostic accuracy of the test.

\section{Diagnoses of VTE}

The incidence of symptomatic VTE - which includes DVT and PE - ranges from 71 to 117 cases per 100,000 of the population. According to studies, which exclude autopsy data, approximately two-thirds of the above mentioned VTE range are DVT and one-third are PE $[44,45]$. In order to diagnose patients with suspected VTE at the primary care level and decide if additional diagnostic measures are necessary, the patient history and clinical examination alone are not sufficient [46,47]. With the introduction of the non-invasive $\mathrm{D}$-dimer blood test, extended to the primary care setting, the accuracy of diagnosis was significantly improved [48-50]. A negative D-dimer test in combination with a low clinical pre-test probability can exclude DVT without requiring an ultrasound [50,51]. In our study, specificity and NPV were good in both groups for the diagnosis of VTE. Sensitivity was slightly better in the control group. The $\mathrm{D}$-dimer assay showed a moderately good specificity while the sensitivity and NPV were excellent: almost all patients with VTE also had an elevated D-dimer. The NPV of $98 \%$ confirms the assay's power in regard to the exclusion of VTE. Here too, the results of the current analysis correspond to the previous study by Tomonaga et al. [10] as well as the findings of other studies, e.g. Ten Cate-Hoek and Prins et al., Leclercq et al. or Schutgens et al. [51-53].

\section{Study limitations and future research}

This study is partially based on a previous prospective multicentre cluster-randomised trial investigating the benefit of POCT-assisted diagnosis for cardiovascular diseases in primary care [10]. The aim of this analysis was to investigate whether the use of the same POCTdevice in the controls leads to a similar increase in diagnostic accuracy. A simple, uncontrolled before and after study design was used.

A second limitation concerns the used POCT-device and the interval between sampling year and publication of this second analysis (ca. 6 years): the Cardiac Reader ${ }^{\varnothing}$ used in this study has been already substituted with new and more accurate devices. However, this should not necessarily alter the value of the results in demonstrating the utility of POCT for the evaluation of patients with chest pain and/or dyspnoea at primary care, since the new device should be more accurate, reducing the percentage of false positive and false negative diagnoses.

Third, our study restricted its geographic scope to Canton of Zurich. Although the results can be assumed to apply to more rural areas as well, this would need to be confirmed in a further study. Forth, the recruiting of patients proved to be surprisingly difficult. Especially in the first phase, the initial number of recruited patients was low and we had to call the physicians several times to remind them to continue patient recruitment. In the second phase with the POCT device, patient recruiting was greatly improved compared to the previous phase. We surmised that the in-practice presence of the Cardiac Reader ${ }^{\circ}$ automatically made the physicians more aware of the study and increased their motivation to recruit patients. Another reason for the lower than expected recruitment numbers is that patients with chest pain in today's modern medicine tend to directly seek out emergency care. Fifth, the working diagnosis and the confirmed diagnosis were determined by the same physician. An evaluation by an independent second physician was not possible due to data protection concerns. This could have led to underreporting of incorrect working diagnoses, artificially inflating the accuracy of the working diagnoses or resulting in a false low difference 
Citation: Steiner C, Szucs TD, Hug M, Riesen WF, Tomonaga Y (2015) PPOCT-assisted Diagnosis for Acute Coronary Syndrome, Heart Failure and Venous Thromboembolism in Primary Care: A Longitudinal Analysis. J Gen Pract S1: 003. doi:10.4172/2329-9126.S10003

Page 6 of 7

between the study phases. On the other hand, all the results of further ambulatory or inpatient investigations were incorporated in the final assessment, which reduced the risk of potential bias. A sixth and final limitation concerns the general practitioners who ignored the results of the biomarkers, especially in the diagnosis of ACS. It was not clear if this was due to a lack of confidence in the biomarkers and hence a greater weighting of the medical history and clinical examination, or if the physicians incorrectly interpreted the results of the biomarkers. This aspect emphasises the importance of continued education and training of primary care providers.

Very little data has been collected on the socioeconomic benefit of cardiovascular risk stratification in primary care using POCT. A number of studies published to date have analysed the advantages of individual biomarkers, particularly in connection with the reduction of further diagnostic procedures and hospitalisations, which can be presumed to offer socioeconomic benefits [10]. For instance, Ten CateHoek et al. [51] determined that the number of unnecessary ultrasound examinations can be reduced by $30 \%$ for patients with suspected VTE who have a negative D-dimer and a low pre-test probability of VTE. Nielsen et al. [54] concluded from their data that NT-proBNP testing obviated the need for an echocardiogram in $50 \%$ of patients presenting with dyspnoea in primary care practices. A similar study by Siebert et al. $[55,56]$ even registered a $58 \%$ reduction in the number of echocardiograms. Moreover, this study was able to show that $13 \%$ of hospitalisations could be avoided and hospitalisation periods could be shorted by $12 \%$ when the diagnosis was made using NT-proBNP. To identify the true positive socioeconomic benefit of POCT for ACS, HF and VTE in primary care medicine, further studies need to be conducted [10].

\section{Conclusions}

This second analysis based in part on the data of the previously reported study by Tomonaga et al. [10], demonstrated again the benefit of 3-in-1 POCT for cardiovascular risk stratification in primary care medicine. The rapid analysis of the three biomarkers cTnT, NT-proBNP and D-dimers enabled more accurate diagnoses of ACS, HF and VTE. In view of the advantageous socioeconomic potential, a further investigation is already being planned based on the clinical outcome of this study [10].

\section{Competing Interests}

The authors declare that they have no conflict of interest.

\section{Acknowledgements}

We would like to thank all the recruiting physicians as well as the patients who participated in the study for their cooperation.

This work was supported by Roche Diagnostics (Switzerland), which provided all POCT devices, reagents and an unrestricted educational grant.

\section{References}

1. Miwa H, Ghoshal UC, Fock KM, Gonlachanvit S, Gwee KA, et al. (2012) Asian consensus report on functional dyspepsia. J Gastroenterol Hepatol 27: 626641.

2. Bytzer P, Talley NJ (2001) Dyspepsia. Ann Intern Med 134: 815-822.

3. Shaib Y, El-Serag HB (2004) The prevalence and risk factors of functional dyspepsia in a multiethnic population in the United States. Am J Gastroentero 99: 2210-2216.

4. Jones RH, Lydeard SE, Hobbs FD, Kenkre JE, Williams EI, et al. (1990) Dyspepsia in England and Scotland. Gut 31: 401-405.

5. Bernersen B, Johnsen R, Straume B (1996) Non-ulcer dyspepsia and peptic ulcer: the distribution in a population and their relation to risk factors. Gut 38 : 822-825.

6. Hirakawa K, Adachi K, Amano K, Katsube T, Ishihara S, et al. (1999) Prevalence of non-ulcer dyspepsia in the Japanese population. J Gastroenterol Hepatol 14: 1083-1087.

7. Hussain SI, Mehboob M, Khan JA, Naz R (2003) Functional dyspepsia; A common problem in Balochistan. The Professional 10: 294-297.

8. Lu CL, Lang HC, Chang FY, Chen CY, Luo JC, et al. (2005) Prevalence and health/social impacts of functional dyspepsia in Taiwan: a study based on Rome criteria questionnaire survey assisted by endoscopic exclusion among a physical check-up population. Scand J Gastroenterol 40: 402-411.

9. Chua ASB (2006) Epidemiology of functional dyspepsia: A global perspective World J Gastroenterol 12: 2661-2666.

10. Camilleri M, Dubois D, Coulie B, Jones M, Kahrilas PJ, et al. (2005) Prevalence and socioeconomic impact of upper gastrointestinal disorder in the United States: results of the US upper gastrointestinal study. Clin Gastroenterol Hepato 3: 543-552.

11. Li Y, Nie Y, Sha W, Su H (2002) The link between psychosocial factors and functional dyspepsia: an epidemiological study. Chin Med J (Engl) 115: $1082-$ 1084.

12. Koloski NA, Talley NJ, Boyce PM (2002) Epidemiology and health care seeking in the functional GI disorders: a population-based study. Am J Gastroenterol 97: 2290-2299.

13. Mahadeva S, Raman MC, Ford AC, Follows M, Axon AT, et al. (2005) Gastrooesophageal reflux is more prevalent in Western dyspeptics: a prospective comparison of British and South-East Asian patients with dyspepsia. Aliment Pharmacol Ther 21: 1483-1490.

14. Shah SS, Bhatia SJ, Mistry FP (2001) Epidemiology of dyspepsia in the genera population in Mumbai. Indian J Gastroenterol 20: 103-106.

15. Moayyedi P, Forman D, Braunholtz D, Feltbower R, Crocombe W, et al. (2000) The proportion of gastrointestinal symptoms in the community associated with Helicobacter pylori, life style factors and non-steroidal anti-inflammatory drugs. Leeds HELP Study Group. Am J Gastroenterol 95: 1448-1455.

16. Tougas G, Chen Y, Hwang P, Liu MM, Eggleston A (1999) Prevalence and impact of upper gastrointestinal symptoms in the Canadian population: finding from the DIGEST study. Domestic/International Gastroenterology Surveillance study. Am J Gastroenterol 94: 2845-2854.

17. Drossman DA, Li Z, Andruzzi E, Temple RD, Talley NJ, et al. (1993) Householder survey of functional gastrointestinal disorder. Prevalence, Sociodemography and health impact U.S.A. Dig Dis Sci 38: 1569-1580.

18. Malfertheiner $P$ (1999) Current concepts in dyspepsia: a world perspective. Eur J Gastroenterol Hepatol 11 Suppl 1: S25-29.

19. Geeraerts B, Tack J (2008) Functional dyspepsia: past, present, and future. J Gastroenterol 43: 251-255.

20. Giurcan R, Voiosu TA (2010) Functional dyspepsia: a pragmatic approach Rom J Intern Med 48: 9-15.

21. Ranjan P (2012) Non-ulcer dyspepsia. J Assoc Physicians India 60 Suppl: 1315.

22. Holtmann G, Siffert W, Haag S, Mueller N, Langkafel M, et al. (2004) G-protein beta 3 subunit $825 \mathrm{CC}$ genotype is associated with unexplained (functional) dyspepsia. Gastroenterology 126: 971-979.

23. Park HK, Jahng JH, Lee YJ, Park H, Lee SI. (2009) Serotonin transporter gene and G-protein beta 3 (GNB3) subunit C825T gene polymorphism in patients with functional dyspepsia and irritable bowel syndrome. Korean J. Neurogastroenterol. Motil 15: 58-64.

24. Gathaiya N, Locke GR, Camilleri M, Schleck CD, Zinsmeister AR, et al. (2009) Novel association with dyspepsia; a community based study of familial aggregation, sleep dysfunction and somatization. Neurogastroenterol, Motil 21: 922-969.

25. Camilleri CE, Carlson PJ, Camilleri M, Castillo EJ, Locke GR 3rd, et al. (2006) A study of candidate genotypes associated with dyspepsia in a U.S. community. Am J Gastroenterol 101: 581-592.

26. van Lelyveld N, Linde JT, Schipper M, Samsom M (2008) Candidate genotypes associated with functional dyspepsia. Neurogastroenterol Motil 20: 767-773. 
Citation: Steiner C, Szucs TD, Hug M, Riesen WF, Tomonaga Y (2015) PPOCT-assisted Diagnosis for Acute Coronary Syndrome, Heart Failure and Venous Thromboembolism in Primary Care: A Longitudinal Analysis. J Gen Pract S1: 003. doi:10.4172/2329-9126.S10003

27. Arisawa T, Tahara T, Shibata T, Nagasaka M, Nakamura M, et al. (2008) Genetic polymorphisms of cyclooxygenase-1 (COX-1) are associated with functional dyspepsia in Japanese women. J Womens Health (Larchmt) 17: 1039-1043.

28. Zhou Z, Zhu G, Hariri AR, Enoch MA, Scott D, et al. (2008) Genetic variation in human NPY expression affects stress response and emotion. Nature 452 : 997-1001.

29. Jamshid S, Kalantar NJ, Tally. (2007) Towards a diagnosis of functional dyspepsia. Medicine Today 8: 45-50.

30. Moayyedi P, Delaney BC, Vakil N, Forman D, Talley NJ (2004) The efficacy of proton pump inhibitors in nonulcer dyspepsia: a systematic review and economic analysis. Gastroenterology 127: 1329-1337.

31. Redstone HA, Barrowman N, Veldhuyzen Van Zanten SJ (2001) H2-receptor antagonists in the treatment of functional (nonulcer) dyspepsia: a meta-analysis of randomized controlled clinical trials. Aliment Pharmacol Ther 15: 1291-1299.

32. Ray WA, Murray KT, Meredith S, Narasimhulu SS, Hall K, et al. (2004) Oral erythromycin and the risk of sudden death from cardiac causes. N Engl J Med 351: 1089-1096.

33. Bromer MQ, Friedenberg F, Miller LS, Fisher RS, Swartz K, et al. (2005) Endoscopic pyloric injection of botulinum toxin $A$ for the treatment of refractory gastroparesis. Gastrointest Endosc 61: 833-839.

34. Ingle M, Abraham P (2012) Management of functional dyspepsia. J Assoc Physicians India 60 Suppl: 25-27.

35. Rothenberg ME. Cohen MB (2007) An eosinophilic hypothesis for functional dyspepsia. Clin Gastroenterol Hepatol 5: 259-272.

36. Abell T, McCallum R, Hocking M, Koch K, Abrahamsson H, et al. (2003) Gastric electrical stimulation for medically refractory gastroparesis. Gastroenterology 125: 421-428.

37. Lüscher MS, Ravkilde J, Thygesen K (1998) Clinical application of two nove rapid bedside tests for the detection of cardiac troponin $T$ and creatine kinaseMB mass/myoglobin in whole blood in acute myocardial infarction. Cardiology 89: 222-228.

38. Fehr T, Knoflach A, Ammann P, Pei P, Binswanger U (2003) Differential use of cardiac troponin $T$ versus $I$ in hemodialysis patients. Clinical nephrology 59 : 35-39.

39. Dickstein K, Cohen-Solal A, Filippatos G, McMurray JJ, Ponikowski P, et al (2008) ESC Committee for Practice Guidelines (CPG). ESC Guidelines for the diagnosis and treatment of acute and chronic heart failure 2008: the Task Force for the Diagnosis and Treatment of Acute and Chronic Heart failure 2008 of the European Society of Cardiology. Developed in collaboration with the Heart Failure Association of the ESC (HFA) and endorsed by the European Society of Intensive Care Medicine (ESICM). Eur J Heart Fail 29: 2388-442.

40. Ali Ahmed, MD, MPH, FACP (2003) American College of Cardiology/Amercan Heart Association. Chronic Heart Failure Evaluation and Management Guidelines: Relevance to the Geratric Practice. J Am Geriatr Soc 51: 123-126.

41. Stevenson LW (1989) The limited reliability of physical sings for estimating hemodynamics in chronic heart failure. JAMA 261: 884-888.
42. Hobbs FD, Jones MI, Allan TF, Wilson S, Tobias R (2000) European survey of primary care physician perceptions on heart failure diagnosis and management (Euro-HF). Eur Heart J 21: 1877-87.

43. Cleland JG, Swedberg K, Follath F, Komajda M, Cohen-Solal A, et al. (2003) The EuroHeart Failure survey programme--a survey on the quality of care among patients with heart failure in Europe. Part 1: patient characteristics and diagnosis. Eur Heart J 24: 442-63.

44. White RH (2003)The epidemiology of venous thromboembolism. Circulation 17:107: 14-845.

45. Huerta C. Johansson S, Wallender Ma, Garcia Rodrigues LA (2007) Risk factors and short-term mortality of venous thromboemolism diagnosed in the primary care setting in the United Kidgdom. Arch Intern Med.; a67: 935-943.

46. Oudega R, Moons KG, Hoes AW (2005) Limited value of patient history and physical examination in diagnosing deep vein thrombosis in primary care. Fam Pract 22: 86-91

47. Sanson BJ, Lijmer JG, Mac Gillavry MR, Turkstra F, Prins MH, et al. (2000) Comparison of a clinical probability estimate and two clinical models in patients with suspected pulmonary embolism. ANTELOPE-Study Group. Thromb Haemost 83: 199-203.

48. Schutgens RE, Haas FJ, Gerritsen WB, van der Horst F, Nieuwenhuis HK, et al (2003) The usefulness of five D-dimer assays in the exclusion of deep venous thrombosis. J Thromb Haemost 1: 976-981.

49. Oudega R, Moons KG, Hoes AW (2005) Ruling out deep venous thrombosis in primary care. A simple diagnostic algorithm including D-dimer testing. Thromb Haemost 94: 200-205.

50. Wells PS, Owen C, Doucette S, Fergusson D, Tran H (2006) Does this patient have deep vein thrombosis? JAMA 11;295: 199-207.

51. Ten Cate-HoekAJ, Prins MH (2005) Management studies using a combination of D-dimer test result and clinical probability to rule out venous thromboembolism: a systematic review. J Thromb Haemost 3: 2465-2470.

52. Leclercq MG, Lutisan JG, van Marwijk Kooy M, Kuipers BF, Oostdijk AH, et al. (2003) Ruling out clinically suspected pulmonary embolism by assessment of clinical probability and D-dimer levels: a management study. Thromb Haemost 89: 97-103.

53. Schutgens RE, Ackermark P, Haas FJ, Nieuwenhuis HK, Peltenburg HG, et al. (2003) Combination of a normal D-dimer concentration and a non-high pretes clinical probability score is a safe strategy to exclude deep venous thrombosis. Circulation 107: 593-7.

54. Nielsen LS, Svanegaard J, Klitgaard NA, Egeblad H (2004) N-terminal probrain natriuretic peptide for discriminating between cardiac and non-cardiac dyspnoea. Eur J Heart Fail 6: 63-70.

55. Siebert U, Januzzi JL, Beinfeld MT, Cameron R, Gazelle GS (2006) Costeffectiveness of using $\mathrm{N}$-terminal pro-brain natriuretic peptide to guide the diagnostic assessment and management of dyspneic patients in the emergency department. Am J Cardiol 98: 800-805.

56. Ciccone MM, Cortese F, Gesualdo M, Riccardi R, Di Nunzio D, et al. (2013) A novel cardiac bio-marker: ST2: a review. Molecules 18: 15314-15328. 